\section{Complete peace of mind}

To refer your dental implant cases with complete peace of mind, choose Ten Dental+Facial. The multi award-winning team is comprised of highly experienced dental implantologists who have the knowledge and skills to treat both simple and complex cases.

With state-of-the-art practices based in the heart of London, Ten Dental+Facial is proud to offer a seamless referral service that ensures patients benefit from the highest quality care. You also
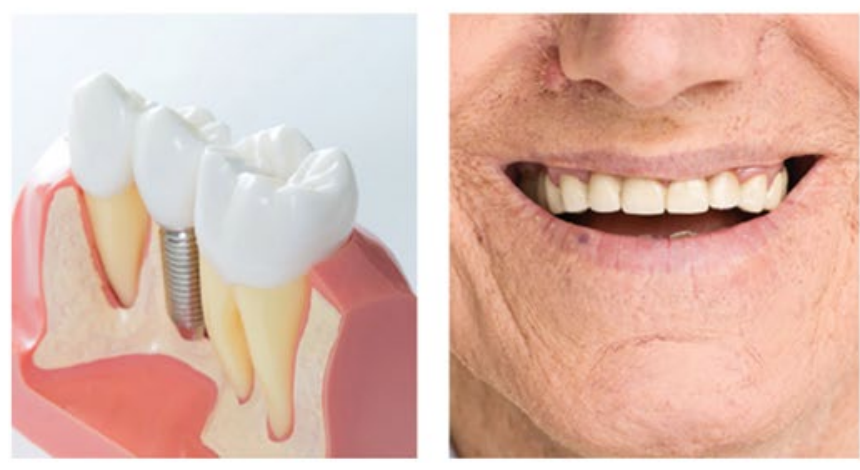

\section{Software now has orthodontic integration}

Dentally is delighted to announce that their e-Ortho integration for NHS Scotland and new orthodontic assessment forms for dental practices across the UK is now live.

This latest product development from the team at Dentally is the design of a new orthodontic feature, whereby assessment data can be recorded within the software.

This new workflow was originally part of the process for their Scottish customers to submit prior approvals and claims for orthodontic work through its e-Ortho integration with NHS Scotland, but the work undertaken will benefit all orthodontic dentists and not just those in Scotland.

The new stand-alone orthodontic module allows for assessment data for values such as overbite and overjet information, recorded by a certain practitioner (and date/time) to be held in a form on a separate tab within Dentally - making it easier to record the data from the outset and track the patient's progress at each stage of their treatment.

The workflow is simple; you just go into the patient's chart and open a treatment plan and chart as normal. You then click on the ortho tab and create a new assessment. It will highlight mandatory fields and when all of the fields are completed, you select save and the information is retained in the ortho tab in Dentally. If you are working in Scotland, then claims can be submitted in two stages and full details are available from the Dentally Support team.

If you would like more information on this, then email hello@ dentally.co. Remember over 7,000 dental professionals are already working smarter, working remotely and working securely with Dentally, so why not book your demo today.

For more information visit: https://dentally.co/ or call 020 38565610 . remain integral to the referral process - no matter whether you choose to refer for comprehensive implant treatment, or for implant surgery with a plan that the patient is returned to you to have their implant restored.

Call Ten Dental+Facial to start referring today.

For more information visit www.tendental.com or call on 020 33932623.
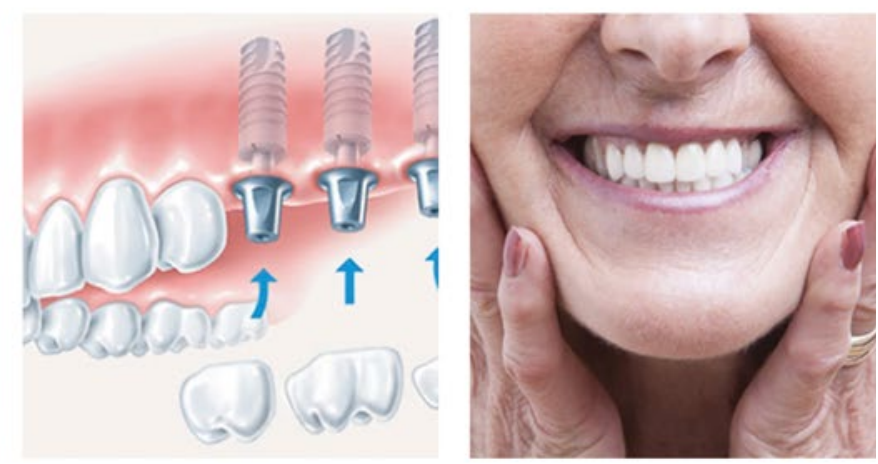

Introducing the UK's biggest orthodontic and splint laboratory

S4S (UK) Limited Dental Laboratory has joined forces with HM Orthodontics London to form the UK's biggest orthodontic and splint laboratory.

S4S and HM Orthodontics have been in discussions over the past 12 months about how best to serve the UK's GDPs and orthodontists. The directors of S4S and HM Orthodontics decided that they could be stronger together and formed S4S London. The acquisition and merger will see dental laboratory giants S4S (UK) Limited and HM London Orthodontics join forces to provide an unrivalled orthodontic service to clients in the South East of England. It opens up a whole new opportunity for dentists and orthodontists to use what will now be the UK's biggest orthodontic laboratory offering the widest range of orthodontic appliances, occlusal splints and mandibular advancement splints.

The acquisition and merger of HM Orthodontics to form S4S London will mean the S4S group will have over 70 staff over the two sites that will be able to take on any amount of work from orthodontists and general dentists. A combination of free post, couriers, delivery drivers, motorcycle and staff using public transport (for Central London customers) will give clients easy access to the best technicians and widest range of services. Existing HM Orthodontic clients will have access to a new range of appliances such as the exclusive SCi occlusal splints, Sleepwell Mandibular Advancement Splint for Snoring and Sleep Apnoea and Smilelign Clear Aligners, not to mention the S4S seminars and training programme. Meanwhile, S4S customers will benefit from the additional wealth of HM Orthodontic's range of appliances and services.

For further information about using S4S London visit s4s. london and request your welcome pack. 